\title{
First Known Case of Juvenile Gigantomachia in the United Kingdom - A Case Report
}

\section{Svenning $\mathrm{M}^{*}$ and Wilson $\mathrm{S}$}

Plastic Surgery Department, Southmead Hospital, North Bristol Trust, Southmead Rd, Westbury-on-Trym, Bristol, United Kingdom

${ }^{*}$ Corresponding author: Svenning M, Plastic Surgery Department, Southmead Hospital, North Bristol Trust, Southmead Rd, Westbury-on-Trym, Bristol, BS10 5NB, United Kingdom, Tel: (+44)07491840380, E-mail: matilda_svenning@hotmail.com

Citation: Svenning M, Wilson S (2019) First Known Case of Juvenile Gigantomachia in the United Kingdom - A Case Report. J Case Rep Stud 7(2): 201. doi: 10.15744/2348-9820.7.201

Received Date: October 07, 2018 Accepted Date: April 24, 2019 Published Date: April 26, 2019

\begin{abstract}
Gigantomastia is a rare condition which remains poorly understood. There is no universally accepted definition, however breast weight exceeding $3 \%$ of total body weight has been proposed. Juvenile gigantomastia, a subtype, involves sudden onset, excessive growth of breast tissue in relation to puberty and can occur before or after the onset of menstruation. This paper reports on the first known case of juvenile gigantomastia seen in the United Kingdom. A 16-year old female presented with a 12-month history of rapid breast growth. She had no other medical problems and no relevant family history. Examination revealed bilaterally enlarged breasts extending to the level of the anterior superior iliac spine, with enlarged superficial veins, ill-defined areola and areas of skin ulceration. A range of hormone and autoimmune tests were performed with all results found to be normal. After MDT discussion, the treatment of choice was reduction mammoplasty with an inferior pedicle technique and free nipple grafting if necessary. The total volume of tissue removed weighed $10.9 \mathrm{~kg} ; 6.6 \mathrm{~kg}$ from the right breast, $4.3 \mathrm{~kg}$ from the left breast. Initial post-operative results demonstrate a highly satisfactory reduction with minimal scarring and no further growth of breast tissue. Histology showed a benign pattern secondary to extensive proliferation of glandular and stromal tissue. The tissue tested positive for both oestrogen and progesterone receptors and so the decision was made to treat the patient with tamoxifen until the age of 21 years in order to prevent recurrence. To our knowledge, this is the first reported case of juvenile gigantomastia in the UK.
\end{abstract}

Keywords: Breast Reduction; Gigantomastia; Juvenile Gigantomastia; Reduction Mammoplasty; Tamoxifen

\section{Introduction}

Gigantomastia is a rare condition characterized by excessive growth of the breast tissue. It has been defined as breast weight that exceeds approximately $3 \%$ of the total body weight, however there is no universally accepted definition and in literature is generally considered as excessive breast tissue of more than $1.5 \mathrm{~kg}$ [1]. Kulkarni et al. define it as bilateral benign progressive breast enlargement to a degree that requires breast reduction surgery to remove more than $1800 \mathrm{~g}$ of tissue on each side. The aetiology for this condition is not clear, but surgery remains the mainstay of treatment [2].

There are five recognized subtypes of gigantomastia; juvenile (also known as pubertal or virginal breast hypertrophy), gestational, idiopathic, penicillin-related and obesity-related [3]. Juvenile gigantomastia is defined as excessive growth of breast tissue in relation to puberty and can occur before or after the onset of menstruation [4]. Defining it retrospectively as weight removed after surgery presents a problem for physicians when clinically diagnosing the condition [5].

The first case of gigantomastia described in medical literature was in 1670 in Plymouth [6]. Gigantomastia can be uni or bilateral, symmetrical or asymmetrical. The breasts grow at an extreme rate causing the skin to stretch, the areola to become less defined, and areas of skin to ulcerate. The cause of the condition remains uncertain but is proposed to be due to increased sensitivity to certain hormones such as estrogen, progesterone, prolactin or growth factors although much of the existing literature reports normal hormone profiles [2,7].

This paper presents the first known case of juvenile gigantomastia reported in the UK.

\section{Case report}

A 16-year old girl presented with extreme breast growth with onset a year prior to presentation at the age of 15 . The patient had onset of menses at the age of 13 years. She had no other health issues and there was no family history of gigantomastia or 
macromastia. Hormone tests including levels of estrogen, progesterone, testosterone, prolactin, LH and FSH were performed together with CA-125 with all results falling within normal limits. The patient also tested negative for autoimmune conditions, including diabetes and hashimotos, as some autoimmune diseases have been linked to gigantomastia in previous cases [8,9].

The patient's pre-surgical weight was $58 \mathrm{~kg}$. On examination, the breasts were bilaterally enlarged and in erect posture reached past the umbilicus to iliac level. Suprasternal notch to nipple distance measured $48 \mathrm{~cm}$ on the right breast and $43 \mathrm{~cm}$ on the left. Both breasts had enlarged superficial veins, ill-defined areola and on the right breast there was an area of ulceration with risk of infection (Figure 1). Before the onset of tissue growth, the patient was allegedly a B-cup in bra size and increased a cup size per month for the following year. On presentation, the condition was severely inhibiting in the patient's everyday life both physically with muscle and back pain and limitation to activity, but also from a psychological perspective with social isolation and withdrawal.

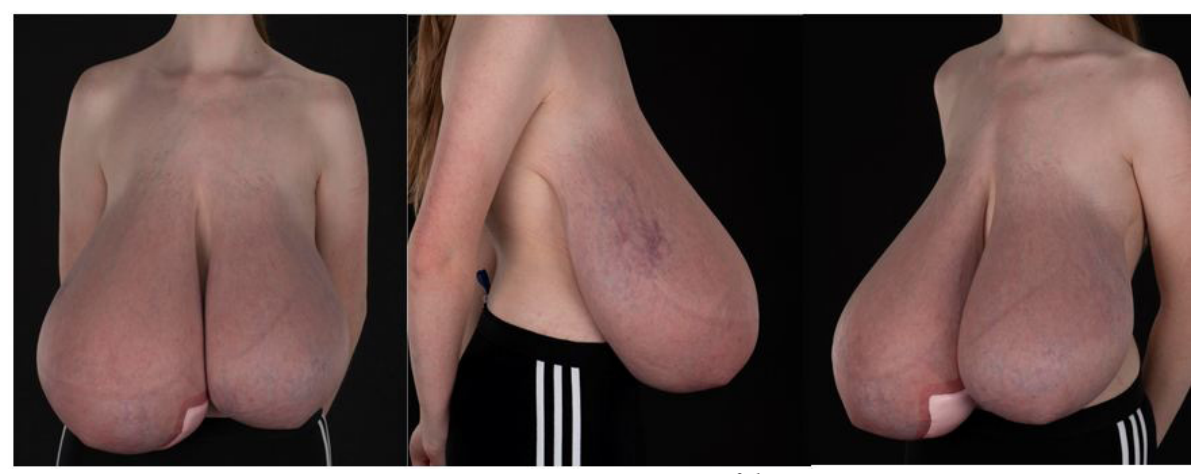

Figure 1: Preoperative assessment of the patient

The case was discussed at MDT and the treatment of choice was reduction mammoplasty with free nipple grafting using a central mound technique under general anesthetic. This was chosen to preserve the shape of the breast while using a reliable blood supply from the perforators of the internal mammary arteries. Due to the large mass of excessive breast tissue creating pedicles $>20 \mathrm{~cm}$ long, nipple preserving surgery was not an option. The volume of tissue removed on the left breast was $4.3 \mathrm{~kg}$, and that on the right breast $6.6 \mathrm{~kg}$ (Figure 2 and 3). Postoperatively the patient was anemic requiring a single transfusion of red bloods cells due to intraoperative bleeding from enlarged superficial veins. There were no other post-operative complications. Histology showed a benign pattern secondary to extensive proliferation of glandular and stromal tissue. There was no chronic inflammatory cellular infiltrate or histologic evidence of malignancy. The tissue was tested for estrogen and progesterone receptors and was positive for both receptors. Previous case reports with positive estrogen receptors have had success using medical post-operative treatment with Tamoxifen to inhibit recurrence [10]. The choice was therefore made to treat the patient with a low dosage of Tamoxifen commencing two weeks postoperatively until the age of 21 years to prevent recurrence.

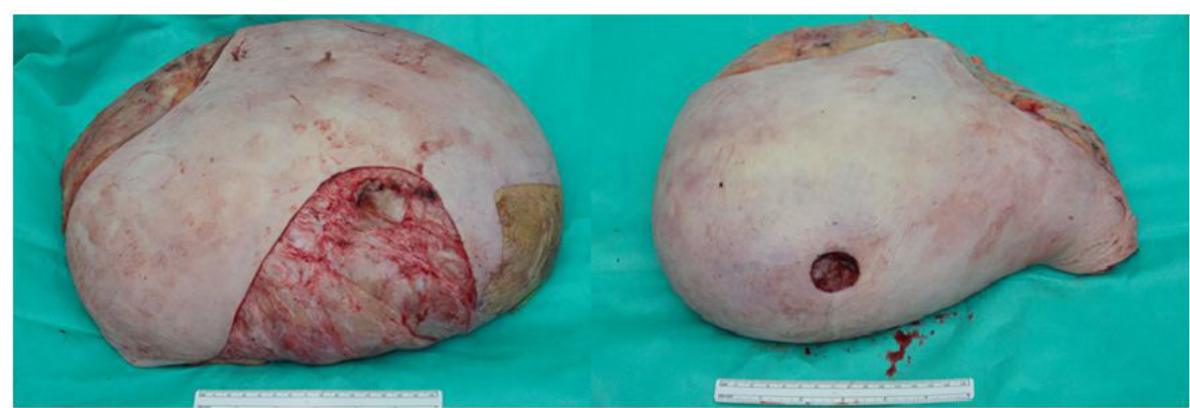

Figure 2: Removed breast tissue

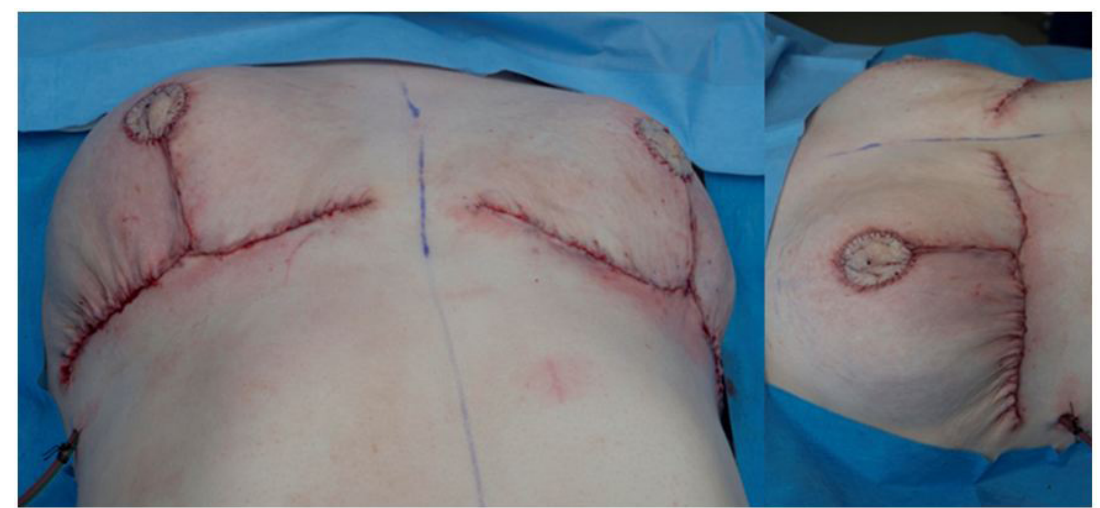

Figure 3: Immediate post-operative results 
On follow up 2 weeks post-surgery the patient presented with healed nipple grafts, minimal scarring, no wound infection and no ulceration. On 3-month post-operative follow up there was no further growth of the breast tissue, the tamoxifen treatment was well tolerated and overall the reconstruction was highly satisfactory. The treatment had a huge positive impact on the patient's physical and psychological state and she has with time been able to return to normal daily activity.

\section{Discussion}

To our knowledge no previous case of juvenile gigantomastia has been reported in the UK. Two studies on gigantomastia from Selly Oak Hospital in Birmingham have been conducted in 2007 and 2010 in the UK. The first study from 2007 was performed to try and define gigantomastia and included a meta-analysis of all previously published cases worldwide, including 7 cases seen in Selly Oak Hospital Birmingham, giving a total of 115 patients. The 7 cases seen in Birmingham were all cases of idiopathic gigantomastia where age of the patients ranged from 26-56 years. The study conducted in 2010 looked to redefine gigantomastia in relation to BMI and was performed on patient data collected from the UK and USA combined. No clear definition of subtype of gigantomastia was given in this article $[1,5]$.

The risks of performing a reduction mammoplasty instead of a bilateral breast amputation were discussed pre-operatively with the patient, her family and at the MDT. When choosing to preserve the breast tissue, there is a risk of recurrence especially during periods when the patient may experience hormonal changes in example pregnancy. The decision to not amputate the breasts was made to try and preserve a natural breast, to preserve the NAC and future lactation ability and sensitivity. Tamoxifen treatment was chosen to minimize the risk of recurrence.

\section{Conclusion}

This article presents a unique case of juvenile gigantomastia seen in the UK. Juvenile gigantomastia remains a rare, poorly understood condition with an arbitrary definition. We believe the treatment of this patient to be successful with no severe short term post-operative complications. Further studies for long term outcome are needed to enhance the understanding of the condition and to optimize the patient treatment for decreasing the risk of recurrence.

\section{Conflict of interest statement}

There was no conflict of interest, financial funding or grants received among the named authors of this case report.

\section{References}

1. Dafydd H, Roehl KR, Phillips LG, Dancey A, Peart F, et al. (2011) Redefining gigantomastia. J Plast Reconstr Aesthet Surg 64: 160-3.

2. Kulkarni D, Beechey-Newman N, Hamed H, Fentiman IS (2006) Gigantomastia: A problem of local recurrence. Breast 15: 100-2.

3. Zargar AH, Laway BA, Masoodi SR, Chowdri NA, Wani AI, et al. (1999) Unilateral gestational macromastia-an unusual presentation of a rare disorder. Postgrad Med J 75: 101-3.

4. Puberty Stages of Developement.

5. Dancey A, Khan M, Dawson J, Peart F (2008) Gigantomastia-a classification and review of the literature. J Plast Reconstr Aesthet Surg 61: 493-502.

6. Durston W (1669) An extract of a letter written to the publisher from Plymouth Novem. 2. 1669. by William Durston Dr. of Physick; Concerning the Death of the Bigg-Breasted Woman (Discoursed of in Numb. 52.) together with what was thereupon observed in her body. Philosophical Transactions of the Royal Society of London 4: 1068-69.

7. Zhong A, Wang G, Yang J, Xu Q, Yuan Q, et al. (2014) Stromal-epithelial cell interactions and alteration of branching morphogenesis in macromastic mammary glands. J Cell Mol Med 18: 1257-66.

8. Touraine P, Youssef N, Alyanakian MA, Lechat X, Balleyguier C, et al. (2005) Breast inflammatory gigantomastia in a context of immune-mediated diseases. J Clin Endocrinol Metab 90: 5287-94.

9. Duffy DA, Demers ML, Molin MR (1995) Systemic lupus erythematosus with breast gigantism. J Rheumatol 22: 1214-5.

10. Baker SB, Burkey BA, Thornton P, LaRossa D (2001) Juvenile gigantomastia: presentation of four cases and review of the literature. Ann Plast Surg 46: 517-25. 


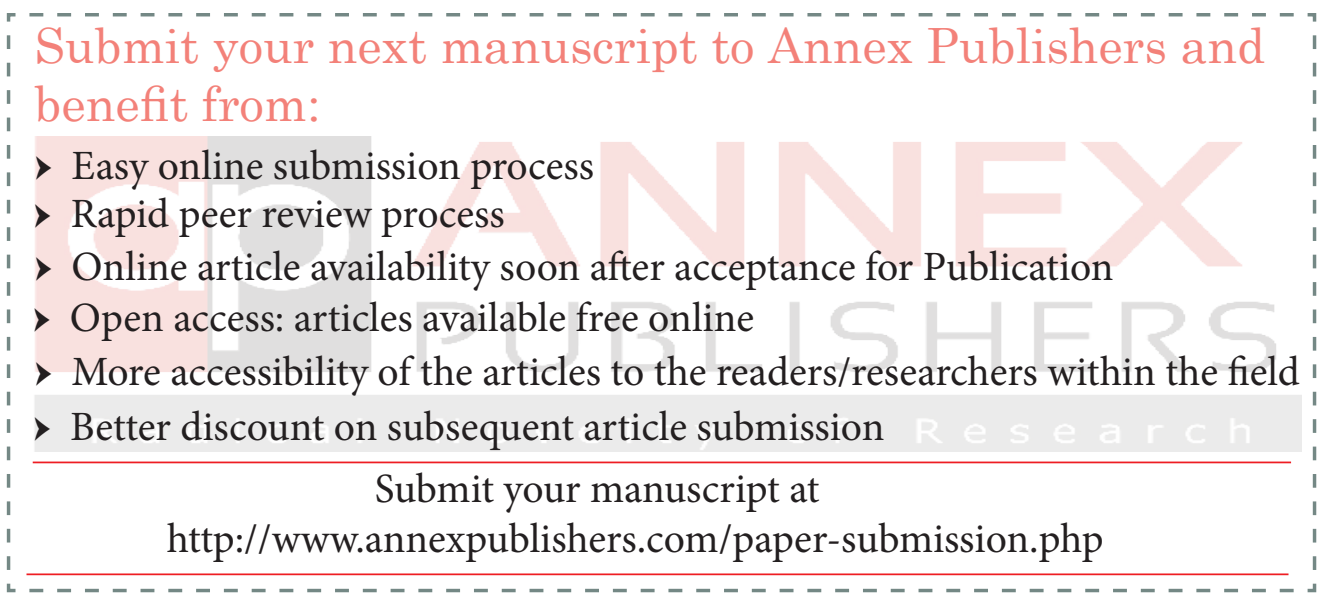

